Erhaltungstherapie bei NSCLC

\title{
Ansprechen abhängig von der Tumorhistologie
}

Ciuleanu T et al. Maintanenance pemetrexed plus best supportive care versus placebo plus best supportive care for non-small-cell lung cancer. Lancet 2009;374:1432-1440

\section{Fragestellung}

Eine Phase-III-Studie ging der Frage nach, ob eine Erhaltungstherapie (Konsolidierungstherapie) mit Pemetrexed direkt im Anschluss an die primäre Kombinationschemotherapie das progressionsfreie Überleben von Patienten mit nicht kleinzelligem Bronchialkarzinom (NSCLC) verbessert. Der Wirkstoff hemmt drei Schlüsselenzyme der DNA- und RNA-Nukleotidsynthese und besitzt ein günstiges Toxizitätsprofil.

\section{Methodik}

In die multizentrische, doppelblinde, randomisierte Phase-III-Studie wurden 663 NSCLC-Patienten (73\% Männer; Durchschnittsalter 60 Jahre; 73\% Raucher, 74\% Nichtplattenepithelkarzinome, davon 50\% Adenokarzinome) aufgenommen. Nach der primären Chemotherapie mit Cis- bzw. Carboplatin und Docetaxel oder Paclitaxel oder Gemcitabin (vier Zyklen) und Erreichen einer Remission bzw. Krankheitsstabilisierung erhielten sie entweder eine Erhaltungstherapie mit
Pemetrexed $\left(500 \mathrm{mg} / \mathrm{m}^{2}\right.$, alle drei Wochen) bis zur Tumorprogression bzw. bis zum Auftreten nicht tolerabler Toxizitäten trotz zweimaliger Dosisreduktion oder Placebo.

Im Pemetrexedarm wurden im Median fünf Zyklen ( $48 \% \geq 6$ Zyklen; $23 \%$ $\geq 10$ Zyklen) und im Placeboarm 3,5 Zyklen $(27 \% \geq 6$ Zyklen; 9\% $\geq 10 \mathrm{Zy-}$ klen) gegeben. Nur bei 5\% der Patienten in der Pemetrexedgruppe war eine Dosisreduktion erforderlich.

\section{Ergebnisse}

Therapieabbrüche wegen Toxizitäten erfolgten bei $5 \%$ der Patienten unter Pemetrexed und bei $1 \%$ der Patienten unter Placebo. Therapieassoziierte Todesfälle traten nicht auf.

Unter Pemetrexed zeigte sich im Vergleich zu Placebo ein signifikanter Vorteil für

_das progressionsfreie Überleben (4,3

vs. 2,6 Monate; $\mathrm{p}<0,0001)$ und

_das Gesamtüberleben (13,4 vs. 10,6

Monate; $\mathrm{p}=0,012 ;$ Abb. 1).

\section{Gesamtüberleben nach der Erhaltungstherapie}

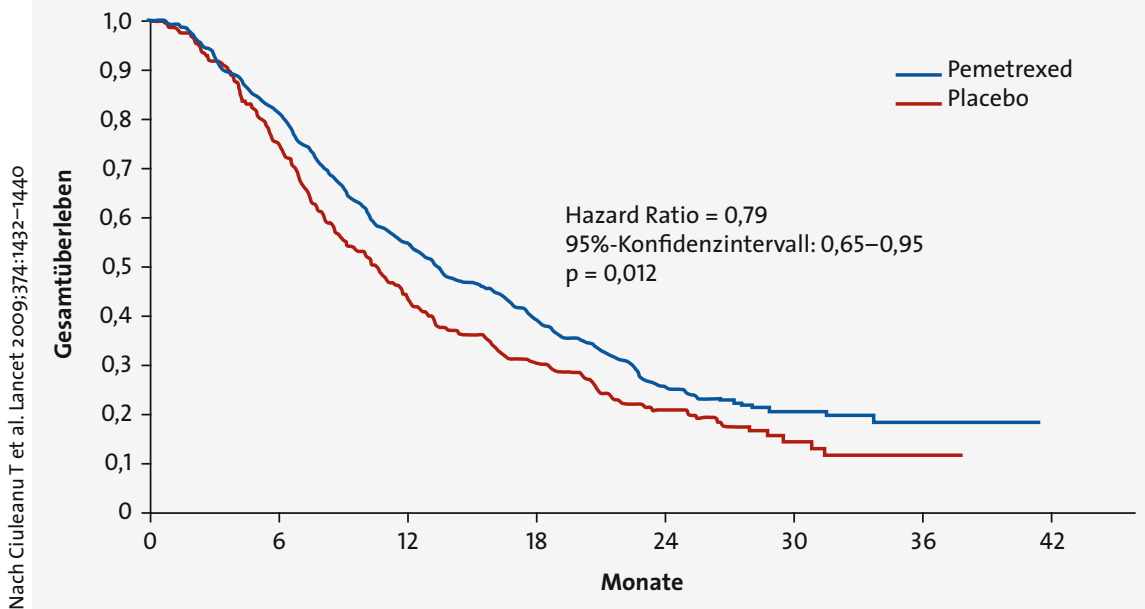

In einer Subgruppenanalyse zeigte sich kein Effekt bei Plattenepithelkarzinomen $(n=182)$, jedoch ein signifikanter therapeutischer Nutzen für Nichtplattenepithelkarzinome (überwiegend Adenokarzinome; $\mathrm{n}=481$ ) mit einem Gesamtüberleben von 15,5 versus 10,3 Monaten $(\mathrm{p}=0,002)$.

\section{Kommentar}

Prof. Dr. med.

Martin Kohlhäufl,

Stuttgart-Gerlingen

Die Studie zeigt, dass NSCLC-Patienten mit Nichtplattenepithelkarzinomen, die primär nicht mit Pemetrexed behandelt wurden, von einer Konsolidierungstherapie mit Pemetrexed profitieren.

Ein möglicher Grund für das bessere Therapieansprechen bei Adenokarzinomen ist die unterschiedliche Expression des Enzyms Thymidilatsynthase (TS), die bei Plattenepithelkarzinomen im Vergleich zu Adenokarzinomen signifikant erhöht ist [3]. Eine hohe TS-Expression ist mit einer reduzierten Sensitivität auf Pemetrexed korreliert.

Wünschenswert für zukünftige Studien wäre, die Patientengruppen so zu charakterisieren, dass eine zeitnahe bzw. verzögerte Zweitlinienbehandlung (Konsolidierungstherapie vs. Zweitlinientherapie) festgelegt werden kann.

Insgesamt ist der Vorteil einer Pemetrexedtherapie bei Adenokarzinomen in der Konsolidierungstherapie überzeugend. Sie ist für Patienten mit gutem Therapieansprechen in der Initialtherapie eine effektive Strategie. 